\title{
Study of mechanical behavior of additive manufacturing bioresorbable polymeric stents models.
}

\author{
Del Monaco ADM*§, Del Monaco MI§, Andrade AJP§, Malmonge SM*. \\ *Federal University of ABC (UFABC), Brazil. § Dante Pazzanese Institute of Cardiology - \\ University of São Paulo (IDPC-USP), Brazil.
}

\begin{abstract}
Stents are devices with important applications in cardiology. They can be used in different cases, as coronary artery disease, peripheral interventions, such as the iliac and carotid arteries, and in very specific applications, as congenital heart disease in aortic coarctation. Studies point to biodegradability of stents as one of the main properties of future generations of these devices. The development of stents made from fully bioresorbable polymeric materials, with appropriate mechanical properties for different applications, is considered an interesting point to be studied. Thus, the objective of this project was to study models of bioabsorbable stents of poly (-L-lactic acid) (PLLA), poly (-L$\mathrm{D}$ lactic acid) (PLDLA) produced by additive manufacturing. The mechanical performances were evaluated by stress and tensile strain tests of different blends compositions of these materials. A heatshock shape memory allocation process and a flexible tube model for simulating implant conditions were developed. PLLA has higher mechanical strength and hardness, while PLDLA is more elastic. Thus, it was possible to study the adequacy of the composition and mechanical properties of the prototypes for each different situation studied (coronary, peripheral and Aortic coarctation implants).
\end{abstract}

Keywords. Bioresorbable stent, coronary artery disease, peripheral arterial disease, Aorta coarctation.

Introduction. Approximately 17.5 million people die due to cardiovascular disease, being the number one cause of death worldwide, according to the World Health Organization (WHO). Among them are coronary heart disease and peripheral arterial diseases. The pathophysiological changes of arterial diseases are related to three fundamental components: the first is endothelial dysfunction, which sets in early, with changes in the reactivity of the vessel due to the characteristics of the inflammatory profile of this process; the second, the loss of natural antithrombotic properties and selective permeability of the endothelium; the third is the obstruction of the vessel lumen by the atherosclerotic plaque that evolves into a possible thrombotic complication at the injury site, and consequent ischemia of the tissue irrigated by that vessel ( $\mathrm{Da}$ Luz et al., 1999; Sionis et al., 2015).

The use of stents is an important strategy in the minimally invasive approach to cardiovascular diseases. The development of fully bioresorbable devices is important in the treatment of different pathologies of the cardiovascular system. In addition to arterial diseases of atherosclerotic origin, stents can be applied in congenital and valve diseases, such as in cases of coarctation of the Aorta and valve disease, with the possibility of implantation of valve stents. For these congenital cases, the issue of patient growth, and the need for re-approaches due to the non-growth of the implants, 
is also an important area of interest in the development of bioresorbable supports (Borhani et al., 2018).

Thus, the development of fully bioresorbable stents is important both for the treatment of vascular diseases of atherosclerotic origin and for the management of congenital diseases, due to the possibility of monitoring growth by new tissues. The focus of the present project is the development of bioresorbable models and the approximation of mechanical properties for each of the three implant possibilities in different cases: coronary artery diseases, peripheral arterial diseases and aortic coarctation.

Coronary artery disease (CAD) is one of the leading causes of death worldwide. It is a disease of multifactorial pathophysiology, with an inflammatory profile, and is directly related to high cholesterol levels in the bloodstream, which starts to form atherosclerotic plaques, obstructing the lumen of the vessels and causing impairments in the supply of oxygen to the tissues it irrigates. (Abu-Assi et al., 2015; Gomes, 2016; Mansur et al., 1996; Libby et al., 1996).

For the treatment of this pathology, three main approaches are known, chosen according to the specific characteristics of each case, by the responsible medical team. A first is clinical treatment, with drugs such as statins, to stabilize parameters. The second option is surgical treatment, with myocardial revascularization using grafts, such as those obtained from mammary arteries and saphenous veins, for example. And a third approach is the minimally invasive treatment by percutaneous intervention, cineangiocoronariography and angioplasty with stent implantation.

Palmaz et al., In 1984, carried out the first experiment with stent implantation, using stainless steel devices contained by a membrane, removed after positioning it inside the atheromatous plaque in coronary disease. This process was a very important step in the treatment of these pathologies, as it addressed the issue of remodeling suffered by the vessel in response to the expansion of the balloon inside. The first coronary stent implantation in Brazil was performed in 1987, at the Instituto Dante Pazzanese de Cardiologia (IDPC), by the team led by Dr. José Eduardo Sousa (Abizaid, 2011; Borhani et al., 2018; Sigwart, 2007; Taylor et al., 1996).

Peripheral arterial obstructive disease (PAD) is the manifestation of degenerative and obstructive atherosclerosis of peripheral arteries in the abdominal, mesenteric, renal, lower limb and carotid vascular territories. This disease has the same characteristics as the inflammatory profile of the disease manifested in coronary arteries and follows the same pattern of evolution, but the peripheral arteries have a significantly larger caliber than the coronary arteries.

The prevalence is three to ten percent in the general population, reaching fifteen to twenty percent in the elderly. Atherosclerotic disease often affects multiple arterial beds simultaneously, and its presence is considered a risk marker for acute myocardial infarction and strokes. It is estimated that forty to sixty percent of patients with peripheral diseases also have CAD or cerebrovascular diseases (American Diabets Association, 2003; Norgren et al., 2007).

The treatment for PAD also follows the same possible approaches for cases of CAD, that is: Clinical treatment using statins, conventional surgery or endovascular. Indications depend on the decision of the medical team for each case, and in cases where clinical treatment and exercise has 
not improved stent implantation is an important alternative (Makdispe et al., 2006; Maleckis et al., 2018 ).

For cases possibly approached by minimally invasive treatments, the use of bioresorbable stents is also an advantage for the treatment of this pathology, since, as in CAD, after the resolution of restenosis by negative remodeling, the endothelization of the stent and the reduction of the proliferative process, make the maintenance of the local presence of the stent unnecessary.

Aortic coarctation is a disease caused by a congenital malformation, which can be associated with anomalies such as stenosis, bivalvular aortic valve, among others. It consists of narrowing the artery in the region between the arch and the descending artery, causing blood flow obstruction, decreased arterial pulse amplitude and, consequently, hypertension, in addition to increased left ventricular afterload (Pedra, 2004; Neves et al., 2005; Brown et. al., 2013).

The consequences of presenting this pathology in for patients can be diverse, such as, for example, development of heart failure, occurrence of stroke, increased prevalence of cases of bacterial endocarditis, in addition to early coronary disease among others (Pedra, 2004 ; Beckmann et al., 2018).

Among the possible treatments are surgical approaches involving the removal of the region of coarctation and end-to-end connection of the vessel. The prevalence of this pathology is 3 cases for every 10,000 births and the first surgical intervention for this case dates back to 1944 (Torok et al., 2015). Another possible approach, depending on the decision of the medical team for each case, is non-invasive interventions, such as stent implantation (Pedra et al. 2005; Vergales et al., 2013).

For those cases where minimally invasive approaches are possible, metallic devices are used for this application. However, when non-resorbable materials are used in pediatric patients, there is an important issue related to patient growth, which is not accompanied by the device. Therefore, the study of bioresorbable materials for this application is also of great importance.

The present project is developed in an attempt to obtain vascular supports that follow the patient's growth or enable new sequential implants in the same region previously addressed, minimizing the risks related to major surgeries and reoperations.

With the implantation of expandable metallic stents by the team of Palmaz and collaborators in 1984, the era of metallic stents, in the English language, bare-metal stents (BMS) began. However, there was no form of treatment in the device for cell proliferation due to the local inflammatory process (Sigwart, 2007; Taylor et al., 1996; Abizaid, 2011; Sigwart, 2007; Taylor et al., 1996).

This process was approached with the use of associated antiproliferative drugs, through coating with biocompatible drug-carrying materials. The second generation of drug-eluting stents in the English language was initiated: drug-eluting stents (DES). In 1999, the first human implant of a DES was performed at the Instituto Dante Pazzanese de Cardiologia, a team also led by Dr. José Eduardo Sousa (Abizaid, 2011; Martin et al., 2011; Pendyala et al., 2009; Sigwart , 2007; Colombo et al., 2003; Zurakowski et al., 2015). 
The first bioresorbable stents, from the English language bioresorbable vascular scaffold (BVS), were developed by Tamai and collaborators, in the early 2000s. They are made of biocompatible and bioresorbable polymeric materials. The main polymers used in the development of bioresorbable stents are Poli (L-lactic acid) and Poli (lactic acid-co-glycolic acid) (PLLA and PLGA). Bioresorbable stents are temporary devices that offer transient mechanical support, in addition to the incorporation of antiproliferatives, as in the second generation, being totally degraded and absorbed by the body in an average time of 2 to 3 years. (Abizaid et al., 2015; Borhani et al., 2018; Farag et al., 2016; Nordmann et al., 2006; Onuma et al., 2011; Tamai et al., 2000).

The first bioresorbable stents commercialized were those from the Abbot ${ }^{\circledR}$ laboratory in 2011 and released for use in Brazil by the National Health Surveillance Agency (ANVISA) in 2014, and the first implantation procedures for these devices were performed by the team of Dr. Alexandre Abizaid, also at the Instituto Dante Pazzanese de Cardiologia (Abizaid et al., 2015; Giessen et al., 1996; Kraak et al., 2015; Lakovou et al., 2005; Licoff et al., 1997; Mani et al., 2007; Newby et al., 2000; Onuma et al., 2011; Taylor et al., 1996; Zurakowski et al., 2015).

Stack and collaborators were the first to perform bioresorbable stent implants in experimental animal models made of PLLA. These devices are widely used in different applications in cardiology, in peripheral arterial diseases, such as disorders in the femoral, carotid, iliac arteries, among others, and the coarctation of the Aorta artery. Supports for tissue engineering, new biomaterials and stem cell implants have been the target of growing studies and development of new technologies in the field of Cardiology (Mantakaki et al., 2018).

Thus, for applications in different pathologies, stents must have properties suitable for each situation. Factors such as the decrease in nail thickness and hardness are critical in applications in coronary arteries, however, in Aorta and peripheral arteries they are not so relevant due to their greater caliber. The focus of the present study is the combination of polymers of the lactic acid family, which have the appropriate properties for each application mentioned.

Materials and methods. The materials Poly (L-lactic acid) (PLLA) and Poly (L-D-lactic acid) (PLDLA) were used to prepare the following studies.

PLLA with molar mass distribution 85,000-160,000 and PLDLA with molar mass distribution 120,000 (Biomaterials Laboratory of the Pontifical Catholic University of São Paulo). The films were obtained by solvent evaporation, (chloroform - $10 \mathrm{mg} / \mathrm{mL}$ ), using petri dishes as a mold. To obtain the blends, bench extrusion techniques were used, with double-screw extruder (AX Plásticos $®)$, to obtain the filaments for making the specimens. The specimens were obtained using the "3D printing" additive manufacturing technique.

The devices were characterized in terms of morphology, surface and mechanical properties: The samples had their dimensions obtained by digital micrometer (Scarret-796). 
TAS Journal, vol. 4, n. 1, p. 38-51

ISSN 2595-1521

MARCH 2020

adriana.delmonaco@usp.br

The mechanical properties were evaluated by tensile testing using a universal testing machine (Instrom-3369). From the stress strain graph, the parameters are determined: elastic modulus, stress and yield strain, stress and rupture strain.

For the statistical analyzes referring to the results obtained in the mechanical tests, the SPSS program (Release 8.0, Standard Version, 1997) was used. All results will be presented as the arithmetic mean plus the standard deviation. The statistical differences between the experimental groups were detected after analysis of variance (One-Way ANOVA) followed by the MannWhitney test. Values of $\mathrm{p} \leq 0.05$ were considered significant.

A technique for "shape memory" of the prototypes was developed based on thermal shock. The prototypes were made in flat film format. The films were wrapped around a cylindrical metal guide and fixed with plastic tape around the substrate to maintain the desired shape of a tube.

After fixing, the set is immersed in water at $80^{\circ} \mathrm{C}$ for 30 seconds. Right after it is immersed in water with ice at $0^{\circ} \mathrm{C}$ for 30 seconds. This process is carried out only once and after the "thermal shock" the prototype is removed from the substrate and it is possible to observe that it now has the "shape memory" for a tube, a feature much closer to the devices used commercially.

During the third semester of the project, the development of models of arteries of different calibers was included to simulate the positioning of the devices and to enable future implant tests, in addition to more practical verification of the shape impression. The models were made by rapid prototyping ("3D printing") using the Thermoplastic Polyurethane (TPU) material, which has flexible characteristics.

Results and discussion. For making the filaments by extrusion, the following parameters were used for the PLLA: Feed zone $190^{\circ} \mathrm{C}$, degas zone $195^{\circ} \mathrm{C}$ and compaction zone $215^{\circ} \mathrm{C}$, speed $15 \mathrm{rpm}$ and torque of $39 \mathrm{NM}$. As for the PLDLA: Feeding zone $135^{\circ} \mathrm{C}$, degassing zone $165^{\circ} \mathrm{C}$ and compaction zone $185^{\circ} \mathrm{C}$, speed $15 \mathrm{rpm}$ and torque of 39NM.

Standardizations were carried out that enabled the production of models by the additive manufacturing technique (3D printing), using the D-Force equipment (FLSUN - Normal DFORCE Kossel 3D Printer), optimizing the parameters: Head temperature, table temperature and print speed.

For the PLLA the head temperature scan was between 180 and $210^{\circ} \mathrm{C}$, with $\sim 5^{\circ} \mathrm{C}$ intervals and the best temperature was $210^{\circ} \mathrm{C}$. For the table temperature the sweep was $50-60^{\circ} \mathrm{C}$ and the best result was obtained with $60^{\circ} \mathrm{C}$. The printing speed varied from $100 \%$ to $45 \%$. The best results were obtained using a speed of $45 \%$ for the first two layers and then $70 \%$ for the following layers. Preliminary results are shown in Figure 1.

For the PLDLA the head temperature scan was between 140 and $180^{\circ} \mathrm{C}$, with $\sim 5^{\circ} \mathrm{C}$ intervals and the best temperature was $178^{\circ} \mathrm{C}$. For the table temperature, the sweep was $50-60{ }^{\circ} \mathrm{C}$ and the best result was obtained with $50^{\circ} \mathrm{C}$. The printing speed varied from $100 \%$ to $45 \%$. The best 
results were also obtained using a speed of $45 \%$ for the first two layers and then $70 \%$ for the following layers. Preliminary results are shown in Figure 1.

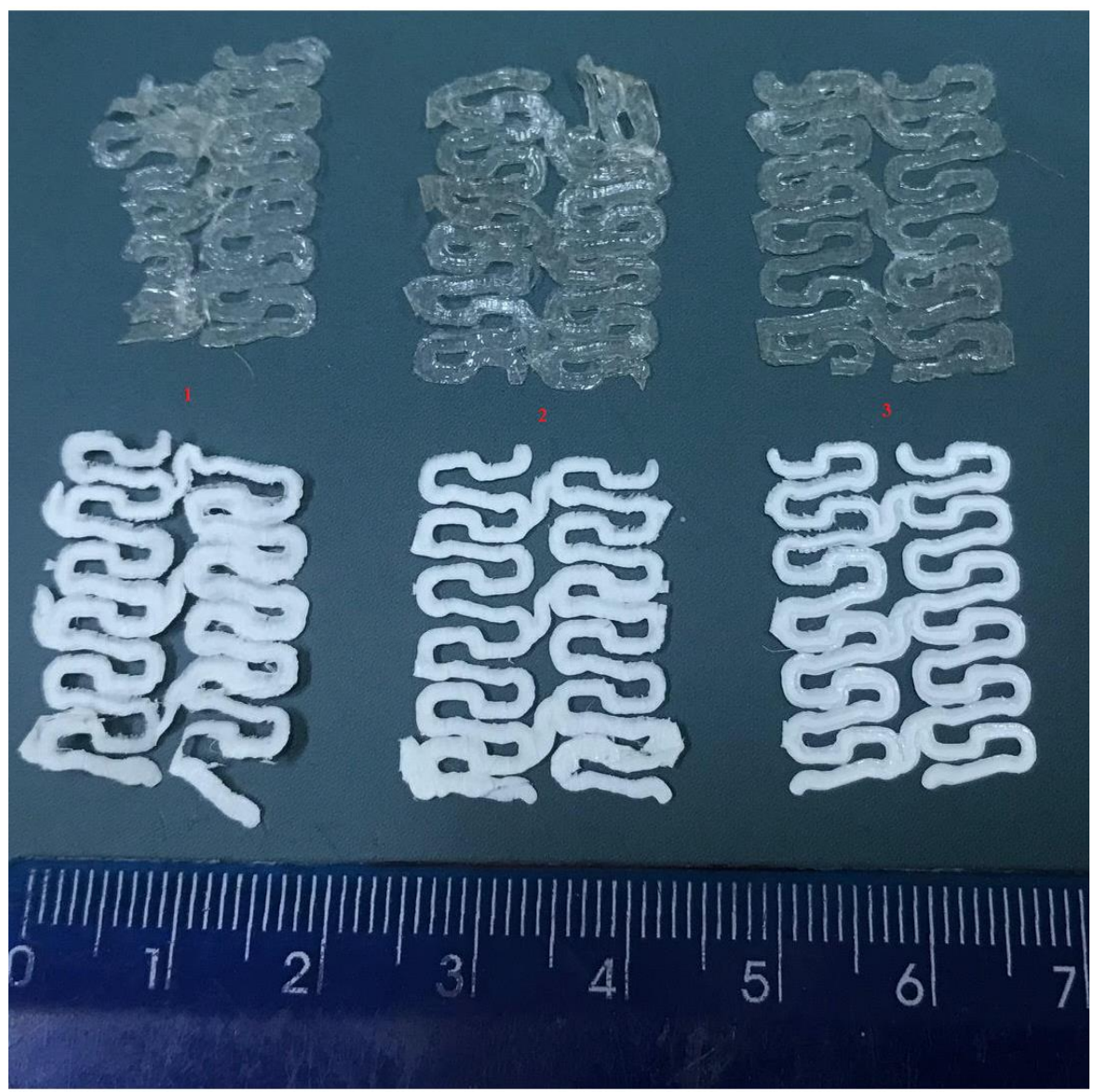

Figure 1: Evolution of the sample standardization process: PLDLA (upper part Transparent color samples) PLLA (lower part - White color samples), the column numbers, 1, 2 and 3, identify samples made under different conditions tested.

It is possible to identify an improvement in the resolution of the drawings gradually, where the samples identified by the number 3, in Figure 1, have more defined edges and less defects in relation to the samples identified by the number 1 . The samples with the best resolution were obtained with the standards identified as ideal for each material.

The process developed for making the tubular prototypes can be considered satisfactory. The tubes developed had "shape memory" and when submitted to preliminary manual compression tests, they returned the initial conditions as expected. In Figure 2 it is possible to observe the developed process: in 1 the device right after the prototyping (in flat format), in 2 we have the prototype after coupled to the guide, the coupling is done with the aid of a plastic film of Poly Propylene, in 3 the device just after the thermal shock, already with the shape memory, in the same figure, on the right side, we have the metallic guide used. 


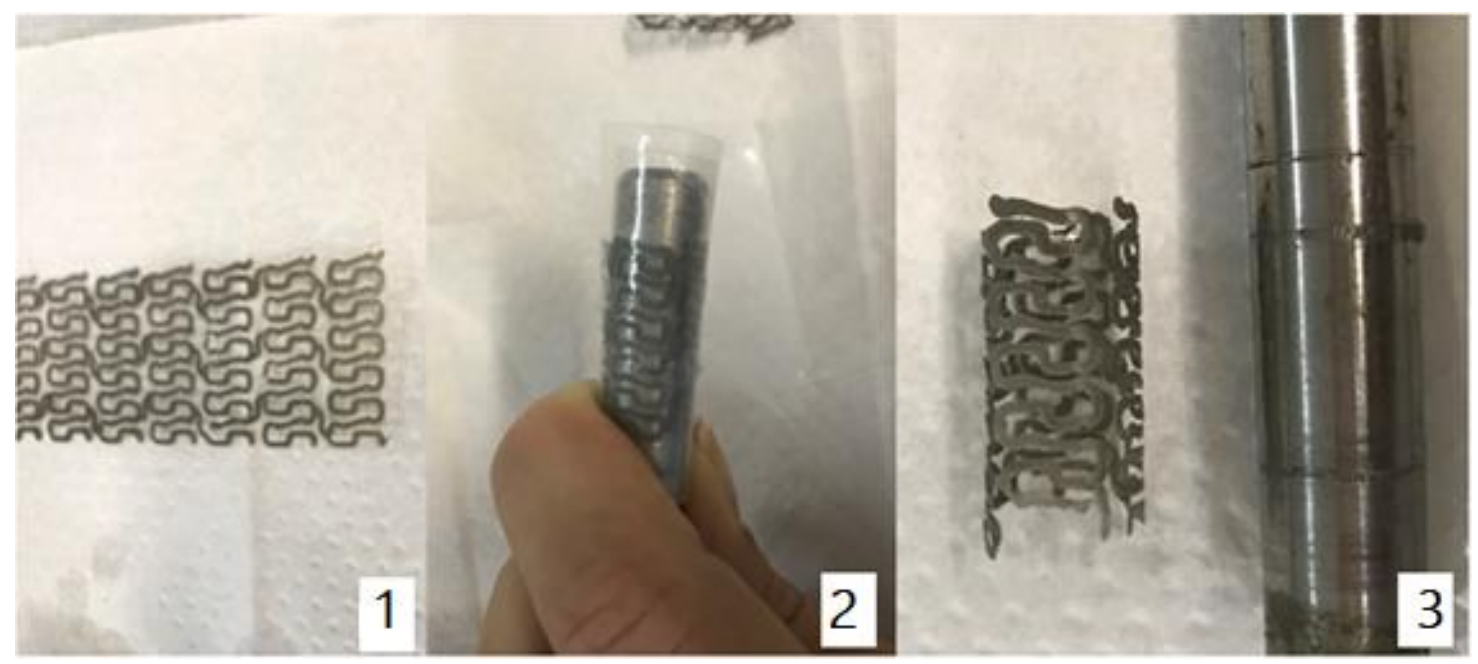

Figure 2: Item 1: Prototype after 3D printing, flat. 2: Prototype attached to the metallic guide. 3: Prototype after thermal shock, already in the shape of a tube.

The artery models of different sizes developed showed efficiency in these preliminaries performed, shown in Figure 3. Models of different sizes were made, ranging from $0.5 \mathrm{~cm}$ to $2 \mathrm{~cm}$ in diameter.
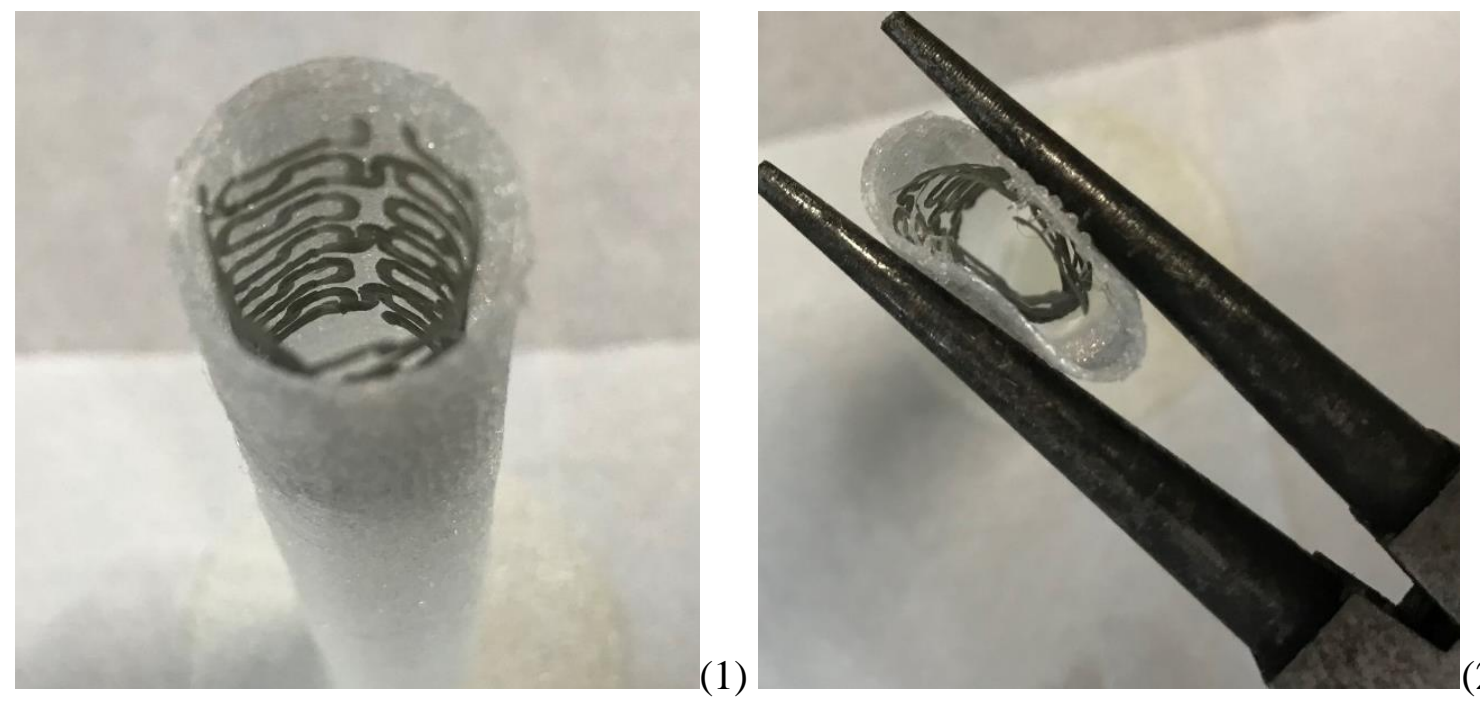

Figure 3: Item 1: Flexible tube containing a stent model (diameter $2 \mathrm{~cm}$ ). 2: Flexible tube containing stent model, being manual compressed.

Different bench tests were carried out, compressing the tube manually with pliers as in Figure 3 in order to check if it would return to its original position, without apparent deformations. These tests were important in confirming the shape memory, since the tested prototypes showed resistance to the "negative remodeling" carried out by compression with the pliers, returning to the initial position without presenting any visually observable deformations. Further complementary tests 
will be carried out in the future, such as resistance to fatigue and compression. Biomodels obtained by additive manufacturing, 3D printing, have been shown to be efficient and important in stent implant testing and training (Sun et al., 2019).

The films presented thickness values between 0.29 and $0.18 \mathrm{~mm}$, with a very small standard deviation, which proves the thickness uniformity of the samples obtained by the additive manufacturing method (3D printing).

Final mechanical tests were carried out during the course of the second and third semesters of project execution, showing the values of elastic modulus (E), stress and strain in the flow, as well as stress and strain at break, were determined by the data acquisition software equipment manufacturer. The mean values and standard deviations for each sample were determined and the difference between the groups was assessed by analysis of variance and a confidence interval of $p$ $<0.05$ was considered.

PLLA presented the highest values for elastic modulus (1,025.55 Pa), and tensile strength (32.55 Mpa), showing the highest strength among the materials studied. Figure 4. PLDLA presented lower values, and very close to each other., for modulus of elasticity (145.03 Pa) and stress at break (6.32 Mpa), in addition to higher values than PLLA for deformation in flow and break, Figure 5. Thus, with the possibility of blending between the two materials, in any proportion, devices with mechanical properties can be manufactured within the range comprised by the upper (PLLA) and lower (PLDLA) values, enabling the adaptation of the mechanical properties for each desired application, such as coronary, peripheral stent or for coarctation of Aorta. Adequate values for these parameters were obtained by computational and simulation studies to predict fracture and stent strength performed by Everett and collaborators in 2016.

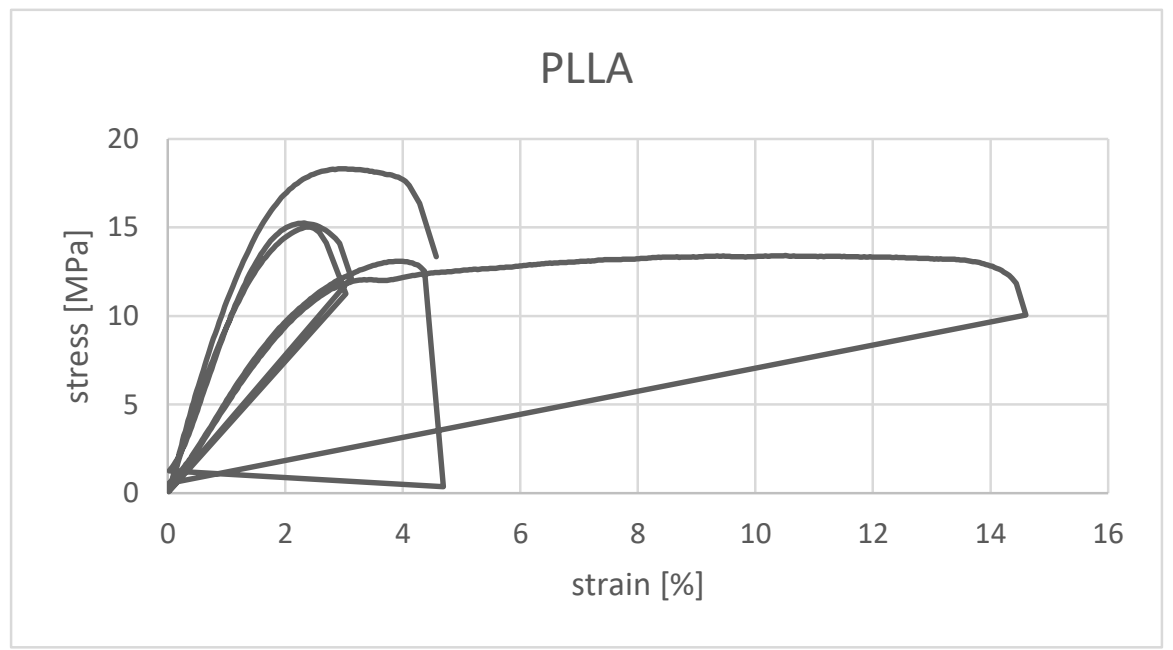

Figure 4: Results of the stress x strain strain test: Stress graph [MPa] x strain [\%] for PLLA. 


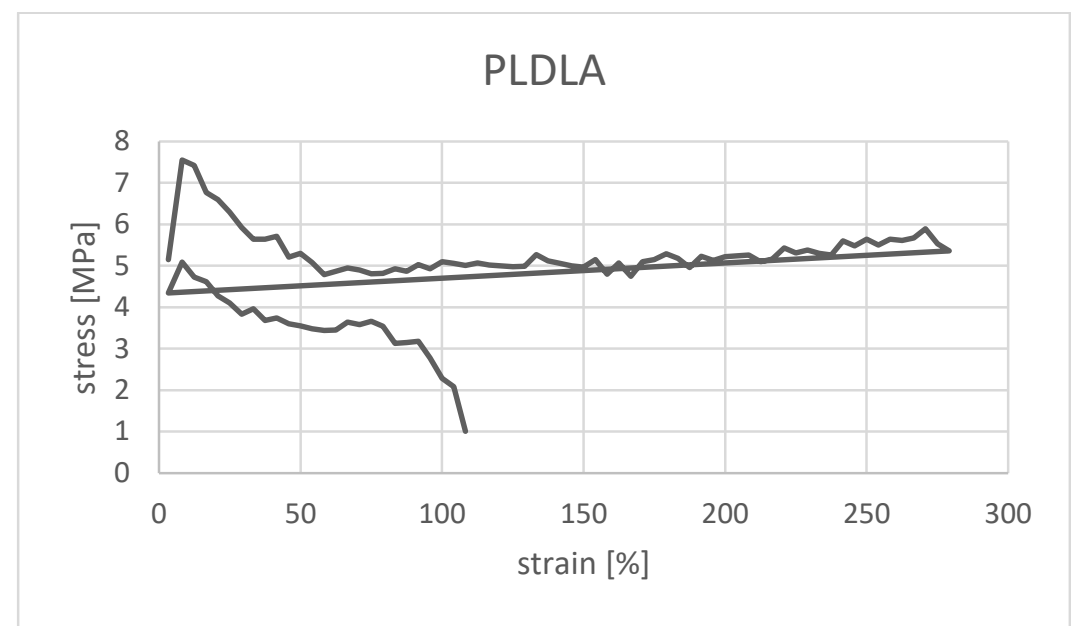

Figure 5: Results of the stress x strain strain test: Stress graph [MPa] x strain [\%] for the PLDLA. Therefore, the greater the proportion of PLLA, the greater the hardness and the maximum tensile strength, Figure 6, properties desired for peripheral devices, which must withstand the radial compression force performed by the larger caliber vessels. In turn, the greater the amount of PLDLA, the more elasticity the device will have, approaching the desired properties for a coronary device (Everett et al., 2016), preventing it from "breaking" after implantation, Figure 7.

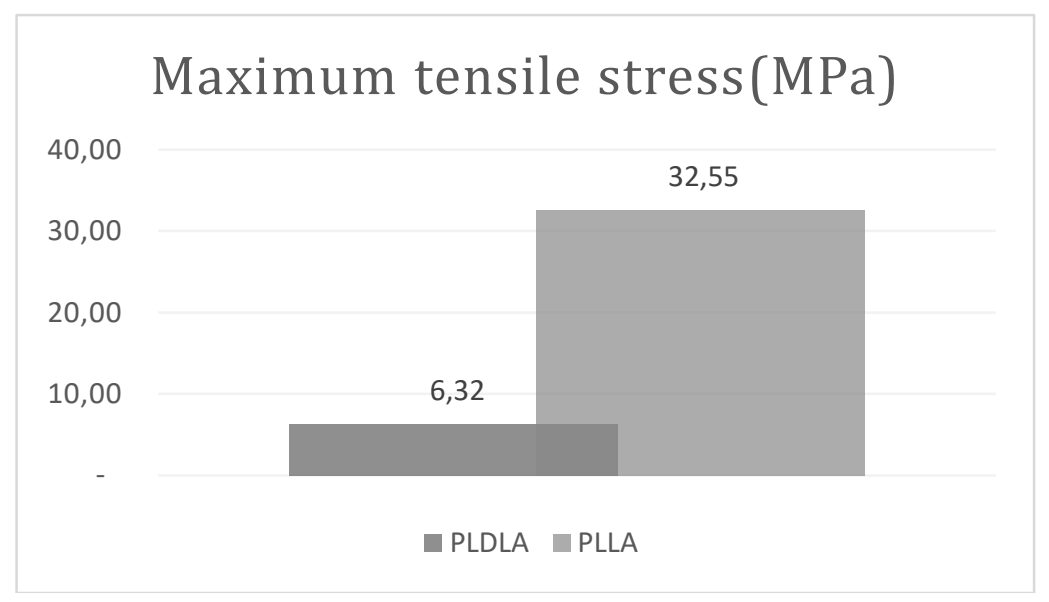

Figure 6: Results of maximum tensile stress, obtained through the evaluation of stress $\mathrm{x}$ strain strain tests for PLLA and PLDLA. 


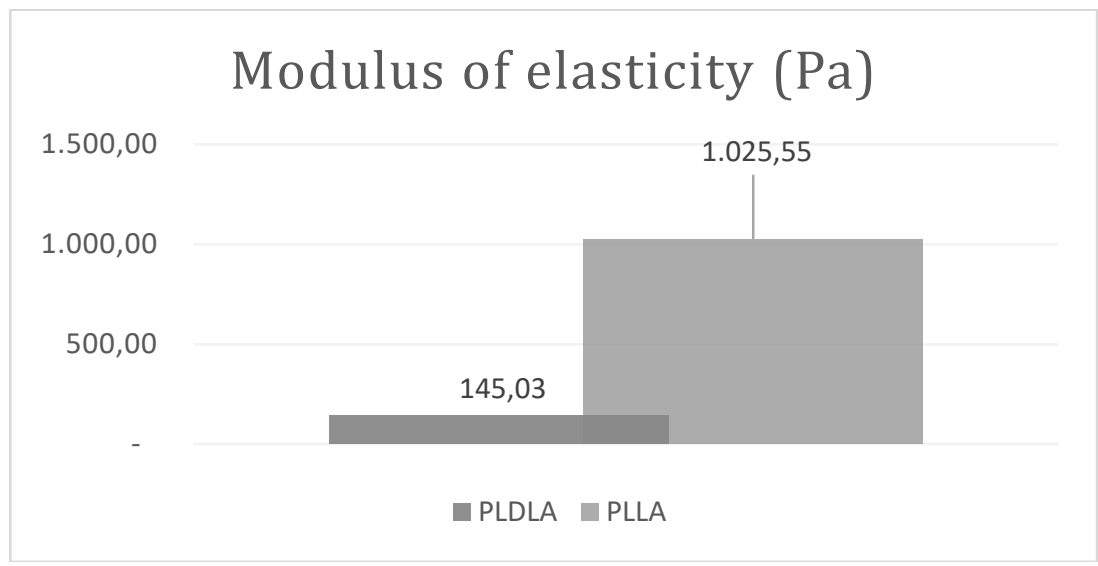

Figure 7: Results of modulus of elasticity, obtained through the evaluation of stress x strain strain tests for PLLA and PLDLA.

Finally, intermediate properties are expected for devices made for the treatment of coarctation of the Aorta, with wide variation in size, depending on the age of the patient and according to the evolution of his growth, devices with specific properties for each case can be made.

Conclusion. It was possible to obtain stent models from adaptations and standardization of additive manufacturing techniques for samples of pure PLLA and PLDLA.

It was possible to identify the best conditions for prototyping the materials, including head temperature, table, printing speed and layer overlay rate for each of the studied polymers.

For the next stages of the project, the mixtures between the polymers for making the blends, the standardizations and characterizations, were obtained as expected. PLLA has greater mechanical resistance and hardness, while PLDLA is more elastic. Thus, it was possible to study the adequacy of the composition and mechanical properties of the prototypes for each different situation studied (implants in coronary, peripheral and in coarctation of the Aorta).

It was possible to obtain tubular prototypes with "shape memory", similar to current commercial devices and to test different implant conditions in the developed artery models.

Acknowledgments. This project was carried out in collaboration with the Biomaterials Laboratory of the Federal University of ABC (UFABC), for the preparation of films and specimens, as well as the characterization experiments of the models.

Disclosure. The authors report no conflicts of interest in this work. 


\section{References.}

Abizaid A C. Stents Farmacológicos: Avanços e Perspectivas. Novas Plataformas e Stents Bioabsorvíveis; a Questão do Polímero e Novos Fármacos. Tese de livre docência apresentada à Universidade de São Paulo -SP 2011.

Abizaid A, Ribamar Costa R J Jr, Bartorelli AL, Whitbourn R, van Geuns RJ, Chevalier B, Patel T, Seth A, Stuteville M, Dorange C, Cheong WF, Sudhir K, Serruys PW; The ABSORB EXTEND study: preliminary report of the twelve-month clinical outcomes in the first 512 patients enrolled. EuroIntervention. Apr;10(12):1396-401. doi: 10.4244/EIJV10I12A243, 2015.

Abu-Assi E, Castiñeira-Busto M, González-Salvado V, Raposeiras- Roubin S, Riziq-Yousef Abumuaileq R, Peña-Gil C, Rigueiro-Veloso P, Ocaranza R, García-Acuña JM, GonzálezJuanatey JR. Coronary Artery Dominance and Long-term Prognosis in Patients With ST-segment Elevation Myocardial Infarction Treated With Primary Angioplasty. Rev Esp Cardiol (Engl Ed). pii: S1885-5857(15)00217-0. doi: 10.1016/j.rec.2015.04.010, 2015.

American Diabetes Association. Peripheral arterial disease in people with diabetes. Diabetes Care. 2003.

Beckmann E, Jassar AS. Coarctation repair-redo challenges in the adults: what to do?. J Vis Surg. 2018;4:76. Published 2018.

Borhani S, Hassanajili S, Ahmadi Tafti SH, Rabbani S. Cardiovascular stents: overview, evolution, and next generation. Prog Biomater. 2018.

Brown, M. L.; Burkhart, H. M.; Connolly, H. M.; Dearani, J. A.; Cetta, F.; Li, Z.; Oliver, W. C.; Warnes, C. A.; Schaff, H. V. Coarctation of the aorta: Lifelong Surveillance is mandatory following surgical repair. J. Am. Coll. Cardiol; 62(11): 1020-1025, 2013.

Colombo A, Drzewiecki J, Banning A, Grube E, Hauptmann K, Silber S, et al. Randomized study to assess the effectiveness of slow and moderate-release polymer-based paclitaxel-eluting stents for coronary artery lesions. Circulation; 108:788-94, 2003.

Da luz P L, Favarato D, Doença coronária crônica. Arq Bras Cardiol volume 72, (nº 1), 1999.

Everett KD, Conway C, Desany GJ, et al. Structural Mechanics Predictions Relating to Clinical Coronary Stent Fracture in a 5 Year Period in FDA MAUDE Database. Ann Biomed Eng. 2016. 
Farag M., Spinthakis N., Gorog D A., Prasad A., Sullivan K., Akhtar Z., Kukreja N., Srinivasan M. Use of bioresorbable vascular scaffold: a meta-analysis of patients with coronary artery disease. Open Heart;3:e000462. doi:10.1136/openhrt-2016-000462, 2016.

Gomes, R. C. Doenças Cardiovasculares Causam Quase 30\% das Mortes no País. Ministério da Saúde, 2014. Disponivel em: <http://www.brasil.gov.br/saude/2011/09/doencas-cardiovascularescausam-quase-30-das-mortes-no-pais >. Acesso em: 20 novembro 2016.

Kraak RP, Hassell ME, Grundeken MJ, et al. Initial experience and clinical evaluation of the Absorb bioresorbable vascular scaffold (BVS) in real-world practice: the AMC Single Centre Real World PCI Registry. EuroIntervention;10:1160-8, 2015.

Lakovou I, Schmidt T, Bonizzoni E, Ge L, Sangiorgi GM, Stankovic G, Airoldi F, Chieffo A, Montorfano M, Carlino M, Michev I, Corvaja N, Briguori C, Gerckens U, Grube E, Colombo A. Incidence, predictors, and outcome of thrombosis after successful implantation of drug-eluting stents. JAMA. May 4;293(17):2126-30, 2005.

Libby P, Ross R. Fuster V, Ross R, Topol EJ. Eds. Cytokines and growth regulatory molecules in Atherosclerosis and Coronary Artery Disease. Vol. I. Philadelphia: Lippincott-Ravn: 585-94, 1996.

Lincoff AM, Furst JG, Ellis SG, et al. Sustained local delivery of dexamethasone by a novel intravascular eluting stent to prevent restenosis in the porcine coronary injury model. $\mathrm{J} \mathrm{Am} \mathrm{Coll}$ Cardiol. 1997;29:808-816, 1997.

Makdispe M., Pereira A C., Brown D P., Borges I., Machado G L., Kiiejer J E., et al. Representando o Projeto Coração do Brasil e o Comitê de Doença Arterial Periférica da Sociedade Brasileira de Cardiologia - SBC/INCOR. Prevalência e fatores de risco associados à doença arterial periférica no Projeto Coração do Brasil. Arq. Bras. Cardiol. 2008.

Maleckis K, Anttila E, Aylward P, et al. Nitinol Stents in the Femoropopliteal Artery: A Mechanical Perspective on Material, Design, and Performance. Ann Biomed Eng. 2018.

Mani G., Marc D. Feldman, Devang Patel, C. Mauli Agrawal, Coronary stents: A materials perspective. 2007.

Mansur AP, Gonçalves EPS, Ramires JAF - Insuficiência coronária crônica.RBM; 53: 194-8. 1996. 
Mantakaki A, Fakoya AOJ, Sharifpanah F. Recent advances and challenges on application of tissue engineering for treatment of congenital heart disease. PeerJ. 2018;6:e5805. Published 2018.

Martin D. M., F.J. Boyle, Drug-eluting stents for coronary artery disease: a review, Med. Eng. Phys. 33 (2) 148-163, 2011.

Neves, J.; Fraga,V.; Silva, R.; Pilla, C. B.; Esteves, C. A.; Braga, S. L. N.; Nunes, G.; Fontes, V. F.; Pedra, C. A. C. Uso de stents no tratamento da coarctação da aorta. Rev. Bras. Cardiol. Invasiva; 13(3): 153-166, 2005.

Newby, A. C. and Zaltsman, A. B., Molecular mechanisms in intimal hyperplasia. J. Pathol., 190: 300-309. doi: 10.1002/(SICI)1096-9896(200002)190:3<300::AID-PATH596>3.0.CO;2-I, 2000.

Nordmann A, Briel M, Bucher HC. Mortality in randomized controlled trials comparing drugeluting vs. bare metal stents in coronary artery disease: a meta-analysis. Eur Heart J;27(23):2784814, 2006.

Norgren I., Hiatt w R., Dormandy J A., Netter M R., Harris K A., Fowker F G R., et al, Inter Society Comunus for Manegement of peripheral arterial disease. (TASCII). Eur. J. Vasc. Endovasc. Surg. 2007; 33 (Suppl I) 51-70.

Onuma Y; Ormiston J; Serruys W P. Bioresorbable Scaffold Technologies. Circ J; 75: 509 - 520 2011.

Pedra, C. A. C. Análise dos resultados imediatos e tardios do tratamento percutâneo da coarctação da aorta em adolescentes e adultos: comparação entre balões e stents. Tese (Doutorado em Ciências) - Departamento de Medicina da Faculdade de Medicina. São Paulo: Universidade de São Paulo, 177p, 2004.

Pedra, C. A. C; Fontes, V. F.; Esteves, C. A.; Arrieta,S. R.; Braga, S. L. N.; Justino, H.; Kambara, A. M.; Moreira, S. M.; Souza, J. F. R. Use of covered stents in the management of coarctation of the aorta. Pediatric. Cardiol.; 26: 431-439, 2005.

Pendyala L. K., X. Yin, J. Li, J.P. Chen, N. Chronos, D. Hou, The first-generation drug-eluting stents and coronary endothelial dysfunction, JACC Cardiovasc. Interv. 2 (12)1169-1177, 2009.

Sigwart, U. (1994), Coronary Stents: Growing Up?. Journal of Interventional Cardiology, 7: 115116. doi: 10.1111/j.1540-8183.1994.tb00894.x, 2007. 
Sionis A, Ruiz-Nodar JM, Fernández-Ortiz A, Marín F, Abu-Assi E, Díaz-Castro O, Nuñez-Gil IJ, Lidón RM. Update on ischemic heart disease and intensive cardiac care. Rev Esp Cardiol (Engl Ed). 68(3):234-41. doi: 10.1016/j.rec.2014.11.008. Epub 2015 Feb 7, 2015.

Sun Z, Jansen S. Personalized 3D printed coronary models in coronary stenting. Quant Imaging Med Surg. 2019.

Tamai H, Gaki K, Kyo E, Kosuga K, Kawashima A, Matsui S, et al. Initial and 6-month results of biodegradable poly-L-lactic acid coronary stents in mans. Circulation;102(4): 399-404, 2000.

Taylor A. Metals. In: Sigwart U, editor. Endoluminal stenting. London: W.B. Saunders Company Ltd. p. 28-33, 1996.

Torok RD, Campbell MJ, Fleming GA, Hill KD. Coarctation of the aorta: Management from infancy to adulthood. World J Cardiol. 2015.

Vergales JE, Gangemi JJ, Rhueban KS, Lim DS. Coarctation of the aorta - the current state of surgical and transcatheter therapies. Curr Cardiol Rev. 2013.

Żurakowski A, Buszman PP, Milewski KP, Janas A, Gorycki B, Kondys M, Gąsior P, Michalak M, Boxberger M, Peppas A, Granada JF, Buszman PE. Stenting and Adjunctive Delivery of Paclitaxel Via Balloon Coating Versus Durable Polymeric Matrix for De Novo Coronary Lesions: Clinical and Angiographic Results from the Prospective Randomized Trial. J Interv Cardiol. 2015 Aug;28(4):348-57. doi: 10.1111/joic.12210, 2015. 